\title{
A COCHRANE METHOD SYSTEMATIC REVIEW OF UNIVERSITY TECH COMMERCIALIZATION RESEARCH
}

\author{
CloviaHamilton \\ Winthrop university \\ Hamiltoncl@winthrop.edu
}

\begin{abstract}
Since 1980 universities have been able to commercialize inventions that their faculty researchers create as per the 1980 Bayh-Dole Act (P.L. 96-517). Research universities can now own and license these inventions to small and well established companies. Since 1980, research universities have used tech commercialization to support their regional economies with product development and sales, and academic entrepreneurship resulting in university spinoffs and start-up business formations. This results in job creation. The technology transfer offices (TTOs) which were established at many research universities to manage this process have been studied quite extensively. However, the foundational elements that fuel successful TTO performance has not been studied comprehensively. Instead, there are numerous fragmented studies that date back to the early 1980s. In addition, there is no agreed upon common theory for studying university technology and how these elemental inputs related to performance outputs. Thus, herein it is advocated that the resource-based view (J. Barney, 1991) and theory on environmental munificence (Castrogiovanni, 1991, 2002) be used as a theoretical framework for researching university technology commercialization. Competitive resources in a more munificent environment can make it easier for an organization to survive and prosper.
\end{abstract}

\section{Keywords}

technology management, technology transfer, technology commercialization, systematic review, meta-analysis, management of innovation, management of new technologies, project and innovation management, $R \& D$

management, management of scientists and engineers

\section{Introduction}

Stanford cell biologist Lubert Stryer and U.C. Berkeley microbiologist Alexander Glazer researched the use of phycobiliproteins found in marine algae as fluorescent markers. Six (6) months later, Stanford licensed the invention to two (2) companies which is now an important tool for cancer detection and blood screening. And this is only one among many such success stories. In fact, for the past 30 years, universities have been in the business of selling research results by licensing technological innovations to well established corporations, small businesses, and/or to university start-up companies that they spin-off (Wiesendanger, 2000).

Since the Morill Act of 1862, established land grant universities have acted as research hubs. In 1980, Congress passed the Bayh-Dole Act ("Bayh Dole Act," 1980) which allowed universities to obtain ownership title to inventions created with government funded research and established technology transfer offices (TTOs) to manage the process of patenting and licensing these inventions. Technology transfer is a subset of technology management (C. Hamilton, 2017a, 2017b). Because of the role of TTOs in enabling and commercializing innovations, a growing number of researchers have examined for example: whether university policies and structures have any effect on academic entrepreneurship (Seashore Louis, 1989); the features of universities that generate the most spin-offs (A. W. Lockett, Mike 2005); factors that enhance university tech transfer (Friedman, 2003); if internal and external factors explain the efficiency of university tech transfer (Siegel, 2003); the level of efficiency that university TTOs in the UK exhibit (Chapple, 2005); the difference between for profit versus traditional nonprofit TTOs, technology licensing for equity strategies and sponsored research licensing strategies (G. D. Markman, Phan, Phillip H., Balkin, David B., Gianiodis, Peter T., 2005); the best incubation models for academic spin-offs (Clarysse, 2007); the most efficient TTOs (Curi, 2012); what technology transfer specialists pay attention to (C. Hamilton, 2015; C. S. Hamilton, David, 2016); and which TTOs are more likely to get better results (González-Pernía, 2013). 
Although there is a large and growing amount of TTO research, there is significant ambiguity surrounding the determinants of TTO performance. As an example, although one study showed that TTO performance in the creation of startups is strengthened by the presence of human capital (Van Looy, 2011), another study found the presence of human capital had little to no effect in relation to startup formations (Hülsbeck, 2013). This simply example suggests that it is unclear what resources are needed to enable strong TTO performance. Thus, the resourcebased view (RBV) (J. Barney, 1991) may be useful in describing why key TTO attributes might be related to performance. The RBV asserts that when organizations possess strategic resources that are valuable, rare, and hard to imitate, higher performance can result. For example, patents are potentially strategic (J. B. A. Barney, A. M. , 2001). The RBV further outlines that human (e.g., scientists), organizational (e.g., positive reputation, plans, systems), and physical (e.g., labs and facilities) resources might be necessary, but not sufficient, for organizations to perform at high levels if they are easy to imitate (J. Barney, 1991). Although the RBV has been applied to university technology commercialization in prior research (J. B. Powers, 2003), findings from single studies often do not generalize to the overall population (Schmidt, 2015). In addition to the RBV, the environment external to the university is an important source of resources; and when environments are more munificent, it makes it easier for an organization to survive and prosper (Castrogiovanni, 1991, 2002). In the context of TTOs, munificent environmental are characterized by industry funding, total research funding, GDP, and regional R\&D intensity. The meta-analysis allows findings from extant research to be combined so that sampling error is minimized, and that estimates of relationships more closely approximate those found in the population.

\section{Hypotheses Development}

A concept model was developed for university technology transfer success based on the RBV. The concept model's constructs, definitions and samples measures are shown in Exhibit 1. The concept model shows inputs into the university technology transfer process. These are resource inputs. A RBV of university technology transfer involves viewing the process from the lens that TTOs require human, organizational, and physical resources to succeed. It was imperative to find studies with empirical measurements of resources that might be important.

Regarding human capital resources, studies were found which empirically measured TTO staff sizes in terms of full time equivalents (FTEs) (Carlsson, 2002; Chapple, 2005; Hülsbeck, 2013; G. D. G. Markman, Peter T.; Phan, Phillip H.; Balkin, David B. , 2005; J. B. M. Powers, Patricia 2005; Siegel, 2003; Van Looy, 2011); TTO legal expenditures (Chapple, 2005; Siegel, 2003); and TTO age (Chapple, 2005; G. D. G. Markman, Peter T.; Phan, Phillip H.; Balkin, David B., 2005; J. B. M. Powers, Patricia 2005). With regard to organizational resources, invention disclosures (Cardozo, 2011; Carlsson, 2002; Chapple, 2005; Hülsbeck, 2013; Rogers, 2000; Siegel, 2003; Sine, 2003; Swamidass, 2009); patent applications filed by the TTO (Cardozo, 2011; Carlsson, 2002; Ho, 2014; Rogers, 2000; Swamidass, 2009) and university owned patents (Cardozo, 2011; Hülsbeck, 2013; J. B. M. Powers, Patricia 2005; Van Looy, 2011) have been measured.

With respect to physical resources, the presence of medical schools and incubators has also been studied (G. D. Markman, Phan, Phillip H., Balkin, David B., Gianiodis, Peter T., 2005; J. B. M. Powers, Patricia 2005; Van Looy, 2011). Further, the theory of environmental munificence (TEM) applies since the environment external to an organization such as a university is an important source of resources, and when environments are more munificent, it makes it easier for an organization to survive and prosper (Castrogiovanni, 1991, 2002). In the context of TTOs, munificent environmental are characterized by total research funding (Chapple, 2005; Ho, 2014; Hülsbeck, 2013; A. S. Lockett, Donald; Wright, Mike; Ensley, Michael D., 2005; J. B. M. Powers, Patricia 2005; Van Looy, 2011), regional GDP (Chapple, 2005; Hülsbeck, 2013), regional R\&D intensity (Chapple, 2005; A. S. Lockett, Donald; Wright, Mike; Ensley, Michael D., 2005) and industry funding (Ho, 2014; J. B. M. Powers, Patricia 2005). These are empirical studies of external resources with respect to university technology transfer.

Exhibit 1 also shows the outputs of the university technology transfer process. These outputs are entrepreneurial spin-off businesses that may be formed (Hülsbeck, 2013; G. D. Markman, Phan, Phillip H., Balkin, David B., Gianiodis, Peter T., 2005; J. B. M. Powers, Patricia 2005; Rogers, 2000; Van Looy, 2011) and related licensing agreements (Chapple, 2005; J. B. Powers, 2003; J. B. M. Powers, Patricia 2005; Rogers, 2000; Siegel, 2003; Sine, 2003; Swamidass, 2009). There may also be licensing deals with established small business enterprises or larger corporations. The primary performance measures for TTOs are licensing revenues (Carlsson, 2002; Chapple, 2005; Ho, 2014; A. S. Lockett, Donald; Wright, Mike; Ensley, Michael D., 2005; G. D. Markman, Phan, Phillip H., Balkin, David B., Gianiodis, Peter T., 2005; J. B. Powers, 2003; J. B. M. Powers, Patricia 2005; Rogers, 2000; Siegel, 2003). 


\section{Method}

There's a large body of university technology transfer research dating back to the 1970s. Between September November 2014, an evidence-based systematic review of university technology transfer literature was conducted to identify, select, appraise and synthesize results from similar separate studies. The review was updated between August and September of 2017. Systematic reviews focus on a specific research question or set of questions. Here, the systematic review was used to test the hypotheses.

Exhibit 1. Definitions and Sample Measures of RBV constructs

\section{Constructs impacting the Tech Transfer process}

\begin{tabular}{|c|c|c|}
\hline \multicolumn{3}{|c|}{ INPUT } \\
\hline Human (H) & $\begin{array}{l}\text { Universities' TTO staff and } \\
\text { legal resources }\end{array}$ & $\begin{array}{l}\text { TTO staff size (FTEs); } \\
\text { TTO age; } \\
\text { TTO legal expenditure }\end{array}$ \\
\hline Organizational (O) & $\begin{array}{l}\text { Universities' internal } \\
\text { organizational resources }\end{array}$ & $\begin{array}{l}\text { Invention disclosures; } \\
\text { Patent applications filed; } \\
\text { Patents owned }\end{array}$ \\
\hline Physical (P) & $\begin{array}{l}\text { Universities' internal physical } \\
\text { resources }\end{array}$ & $\begin{array}{l}\text { Presence of an Incubator; } \\
\text { Presence of a medical school }\end{array}$ \\
\hline External environment (E) & Regional external resources & $\begin{array}{l}\text { Regional GDP; Regional R\&D } \\
\text { intensity; } \\
\text { Total research funding; } \\
\text { Industry funding }\end{array}$ \\
\hline \multicolumn{3}{|c|}{ OUTPUT } \\
\hline Performance (Perf) & $\begin{array}{l}\text { Outcomes of the university } \\
\text { TTO's activities }\end{array}$ & $\begin{array}{l}\text { Overall performance including } \\
\text { Licenses executed; } \\
\text { Licensing revenues; Startups formed }\end{array}$ \\
\hline License (Lic) & & $\begin{array}{l}\text { Licenses executed; } \\
\text { Licensing revenues }\end{array}$ \\
\hline Startups (Start) & & Startups formed \\
\hline
\end{tabular}

Definitions

Sample Measures

Systematic reviews differ from traditional narrative reviews because systematic reviews require the use of a pre-planned standard format and scientific method. In a traditional review, the researchers would generally look for research papers that support or not support the researchers' hypotheses. With regard to the scientific method, there are four (4) steps that differentiate a systematic review from a traditional narrative review. The traditional reviewer: (1) identifies all evidence on the topic; (2) selects evidence that meets inclusion/ exclusion criteria; (3) appraises the quality and validity of the evidence; and (4) summarizes the results. In comparison to the traditional review, in the systematic review, a standard format is used in an effort to conduct a higher quality, more sophisticated, comprehensive, extensive and unbiased review. There is a clearly specified method of identifying, selecting, validating and including information so that it is clear, transparent, recordable and reproducible. The transparency is in the process documented in the protocol for the systematic review. Using a clear and transparent process helps minimize bias and systematic errors in summarizing the evidence. There is also a quantitative synthesis to integrated the information from multiple studies.

The Cochrane Collaborative is a leading international group of medical researchers that conduct systematic reviews on biomedical research. Using their Cochrane Handbook for Systematic Reviews, the first step in this systematic review was to develop a protocol which outlined the steps for doing the systematic review based on the Cochrane Method (Cochrane Handbook for Systematic Reviews of Interventions, 2011). The protocol included data collection, screening the results, abstracting data, appraising the risk of bias, synthesizing the findings, and interpreting the results. 


\section{Data Sources}

In this systematic review, a comprehensive list of phenomenon-specific search keywords was created. Keywords were selected using the Cochrane Collaboration recommended PICO strategy in medical research. The benefit of using the PICO strategy is to ensure a well formulated research question (Cochrane Handbook for Systematic Reviews of Interventions, 2011). In PICO, research questions are broken down into concepts which include the research Population, medical Interventions, Comparisons and research Outcomes. In this study, keywords include concepts related to this study's newly coined 'PRO' which stands for research Population, Resources, and Outcomes: The studies collected for this systematic review have the following PRO components:

$\mathrm{P}=$ technology transfer office staffing Populations

$\mathrm{R}=$ human, organizational, and physical Resources

$\mathrm{O}=$ patenting, patent licensing and startup formation performance Outcomes

In addition, the Cochrane Collaborative recommends that well formulated research questions in biomedical systematic reviews describe the medical exposure or intervention, outcome, setting and population. The setting and population in the following research questions for this study is the university TTOs and their staffs respectively. According to RBV and TEM, the following hypotheses were tested with this meta-analytical systematic review:

- Research Question 1: Are human resources positively related to TTO performance in the areas of patenting, licensing, and generating startups?

- Research Question 2: Are organizational resources positively related to TTO performance in the areas of patenting, licensing, and generating startups? These resources are invention disclosures, patent applications and patents.

- Research Question 3: Are physical resources positively related to TTO performance in the areas of patenting, licensing, and generating startups? These physical resources include incubators and medical schools.

- Research Question 4: Are external environmental munificence positively related to TTO performance in the areas of patenting, licensing, and generating startups?

These research questions were translated into the following general Boolean format that a database could understand: (Population OR synonym1 OR synonym2) AND (Resource1 OR synonym1 OR synonym2) AND (Outcome1 OR synonym1 OR synonym2). Thus, a sample initial search for Research Question 1 would be: (TTO OR "tech transfer" OR "technology management" OR "technology commercialization" OR "technology licensing") AND ("human resource" OR staff OR employee OR "licensing specialist" OR "tech transfer specialist") AND (performance OR licens OR patent OR startup).

The goal was to use the fewest number of concepts as possible to maintain a manageable set of results in the keyword searches. Keyword searches are any type of free text searching conducted to look for words in abstracts and other database fields. Since it takes an extensive amount of time to hand search all of the literature, a search strategy for databases is estimated and this is augmented with enough hand searching to ensure that the systematic review is being conducted in a full and comprehensive manner. Searches were conducted in databases such as Web of Science, Scopus, Business Source Complete, JSTOR, EBSCO Academic Search, Social Science Research Network (SSRN) and Google Scholar. The search strategy was iterative in that a table was created listing the keywords listed in each study; and as new keywords were found, the search strategy was revised using those terms. The search was rerun and documented. The goal was to create an optimal search strategy in order to retrieve useful citations. This process was done for each database. This was a comprehensive systematic literature review of TTO empirical studies.

Thousands of TTO empirical studies were found. Many used data from the Association of University Technology Management (AUTM) Statistics Access for Technology Transfer (STATT) database. Thus, although the Cochrane Method is typically used in the field of medical research, in this study of university technology commercialization, the universities' patenting and licensing may include medical, engineering, basic science, or computer science and other research areas.

The database search for empirical studies was augmented with hand searching that included the reference list of each study. This is called snowballing. Gray literature including dissertations were also searched. This 
electronic search was evaluated against the Sampson (2008) seven (7) key criteria for assessing search quality (Sampson, 2008): “(1) accurate translation of the research question into search concepts; (2) correct choice of Boolean operators; (3) accurate line numbers and absence of spelling errors; (4) an appropriate text word search; (5) inclusion of relevant subject headings; (6) correct use of limits and filters; and (7) search strategy adaptations". The original search for this study was conducted in 2014. In 2016, the seventh of the key criteria was removed as a highly recommended criterion and is now required at the search strategist's discretion (McGowan, 2016). Further, personal contacts in the university technology transfer were used to help identify and find additional empirical studies that should be included in the data. This thorough methodology is required in comprehensive systematic reviews.

\section{Data Collection}

To record all of this data for the systematic review and meta-analysis, the PRISMA method of transparent reporting was used. PRISMA was used to ensure a high quality rigorous review (Moher, 2009). This reporting strategy includes a 27 step checklist which was implemented for the reporting of this study. The PRISMA information flow chart is provided in Exhibit 2. Data was added to a table which included the data that a reference was found and the source of the data (i.e. the database, hand search, internet search or personal contact recommendation). The search strategy used to find each reference (i.e. keywords); and the name of the reference and findings were noted. In order to minimize bias, peer reviewed publications were selected. It was assumed that internal validity, external validity, originality and ethics would have been assessed in the peer review process.

\section{Meta-Analysis}

After completion of the systematic literature review, a meta-analysis was conducted to aggregate the evidence to reveal whether and to what extent the hypothesized relationships exists. A meta-analysis is a statistical analysis of a large collection of results from individual studies. Meta-analyses are useful when seeking to find trustworthy information when there is seemingly too much information. These analyses facilitate the efficient integration of information and can help university technology commercialization managers make better, rational decisions based on the totality of the available evidence. A meta-analysis yields a weighted average effect of the size of a relationship (Schmidt, 2015). The observed effects are correlations between any two variables and they vary randomly around the population 'real' effect.

Fortunately, meta-analyses minimize the impact that sampling and measurement error have on any given study's results because meta-analyses aggregate effects sizes from multiple studies so that small samples do not distort the overall findings and measurement errors are minimized (Schmidt, 2015). The goal is to consider whether the extent of the effects is large enough to matter to TTOs, faculty researchers, other research administrators and research university leaders.

Inclusion-Exclusion Criteria. To be included in the meta-analysis, each study had to contain a correlation among a resource or external environmental munificence measure and a performance measure. As a systematic reviewer, decisions had to be made about which of the studies were similar enough that they could be combined in a metaanalysis so that it could be determined whether or not an effect exists.

It is well known that there will be characteristics that differ in a set of research studies on a similar topic. For example, the characteristics of the study design, study participants, and outcomes may differ. The selected studies have to be similar in some way and the systematic reviewer has to decide whether they are similar enough. The systematic reviewer is also required to decide whether the studies are estimating in whole or in part a common effect. The goal is to combine the results quantitatively to obtain a single summary result. To ensure quality control, duplicate screening was used by having a second researcher independently review the studies as well. Among thousands of TTO studies extracted and screened as noted in Exhibit 2, 18 studies met the criteria. There were 24 studies identified as having relevant measures. However, only the 18 studies that measured TTO human, organizational and physical resources correlated to performance outcomes of licenses executed, licensing revenue and/or startup companies formed were included in this systematic review's meta-analysis. Also note that Carlsson 2002a and 2002b; and Ho 2014a and 2014b are designated as having two (2) studies each because each research team studied two (2) distinct study groups.

Many of the university technology transfer resources are gathered annually during the Association of University Technology Managers (AUTM) annual licensing survey. These human and organizational resources include, but are not limited to inputs such as TTO staff size, licensing legal budgets; and outputs such as the number of patents, licensing deals, licensing revenues and the number of start-up companies formed as the result of the TTO 
licensing patented inventions to them. Physical resources include, but are not limited to, the presence of a medical school and incubator. The external environmental resources include GDP, R\&D intensity and sponsored research funding.

This data was aggregated using a meta-analysis technique to reveal relationships between these resources. Weighted average effect of the size of relationships are found (Schmidt, 2015). The meta-analysis method was chosen because it reduces the impact that measurement error and sampling error have on empirical research results. A meta-analysis can be used to accumulate evidence within a macro research stream; and as a motivator to reevaluate established theories and develop new theories (Combs, 2011). Thus, the first step in the research method was the completion of a comprehensive literature review of TTO empirical studies. Each study had to contain (1) a measure of a university TTO resource or environmental munificence attribute (e.g., university research budget, industry funding, equity licensing, cash licensing, invention disclosures, patents, staff, staff experience, patenting legal expenditures, age of the TTOs, incubators), (2) a measure of performance (e.g., number of startups, licensing), and (3) an effect size estimate (e.g., correlation) of the relationship between an attribute and performance. A search for observed effects pertaining to human $(\mathrm{H})$, organizational $(\mathrm{O})$, physical $(\mathrm{P})$ resources was conducted; and specific organizational resources related to external resources (E) also known as environmental munificence in relation to overall TTO performance (Perf), licensing as a type of performance (Lic) and startups (S) as a type of performance measure. Lic observed effects involved either executed licensing contracts or licensing revenues that were generated.

\section{Exhibit 2. PRISMA Information Flow Chart}

\section{PRISMA FLOW OF INFORMATION}

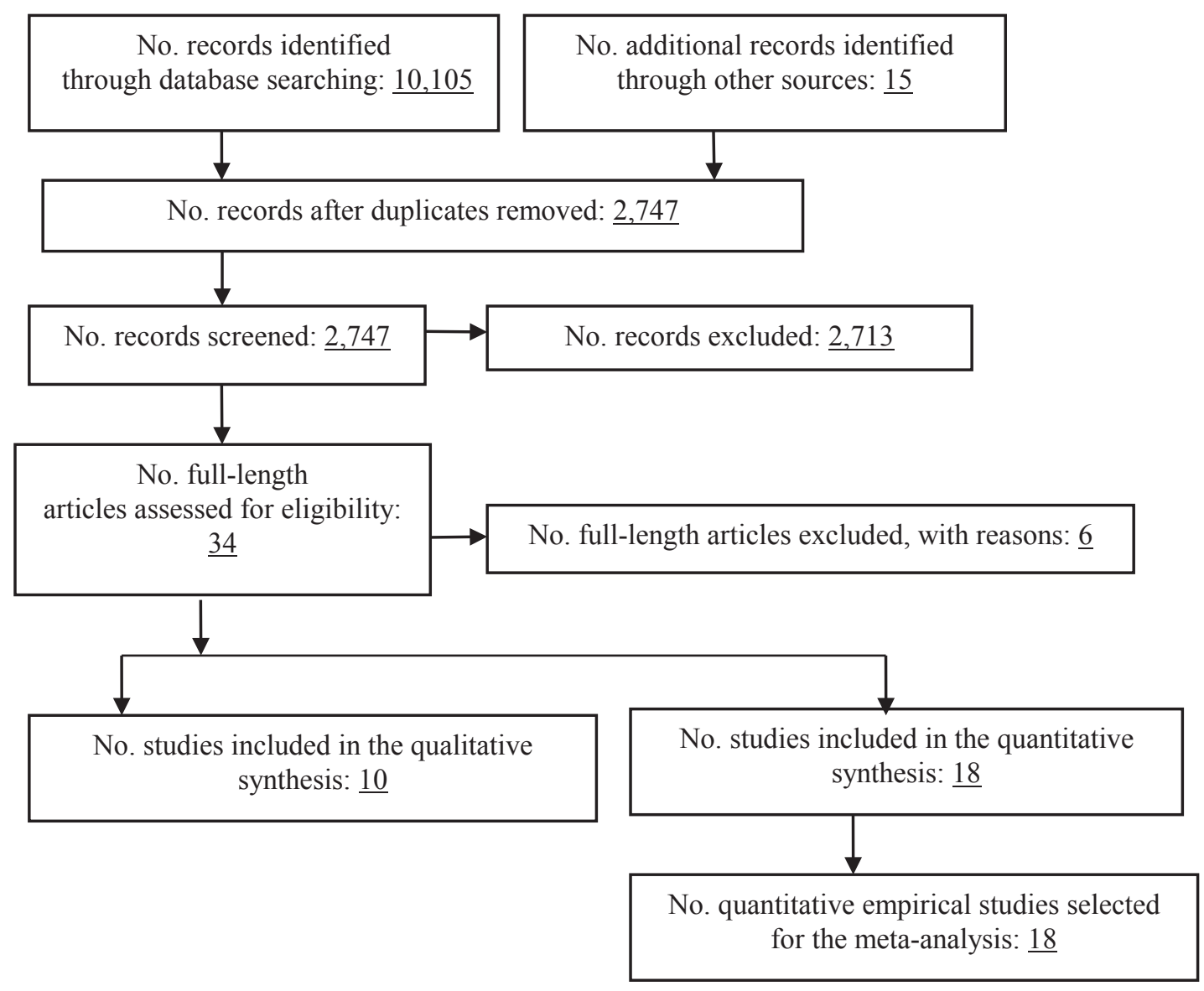

Statistical Analysis. The 18 studies were coded to include identifying data (e.g. author names, publication, year of publication), $\mathrm{N}$ sample size and level of study, independent variables (IV), dependent variables (DV) and correlations (r). Comprehensive Meta-Analysis (CMA) software was used (Borenstein, 2005). Estimates of the 
effect sizes were calculated as the mean of the studies' sample size weighted correlations $(\bar{r})$. This provides a more accurate estimate since positive and negative sampling errors average out (Crook, 2008; Schmidt, 2015). Confidence intervals were used to facilitate hypothesis testing. The predictions were directional and two-tailed tests of the null were used. The effects described in the hypotheses were tested by whether the confidence intervals for $\bar{r}$ included zero.

\section{Results}

Effect sizes are estimates of a relationship's magnitude. A relationship such as a correlation $r$ has a large effect if the observed $r=0.50$ or higher (Cohen, 1977). From the 18 studies found in the literature review, the weighted average effects and weighted average corrected effects were computed using a fixed effects model and are listed in Exhibit 3. The large effect sizes are highlighted in Exhibit 3. In addition, Exhibit 4 provides a comparison of results using the fixed effect model versus a random effects model. Heterogeneity is variation underlying the effects. The random effects model for meta analyses makes allowance for heterogeneity because it assumes there is a distribution of true effects.

Exhibit 3. University technology transfer meta-analysis results using a fixed effects model

\begin{tabular}{|l|l|l|l|l|l|l|l|l|l|l|l|l|}
\hline E & E & E & P & P & P & O & O & O & H & H & H & IV \\
\hline Start & Lic & Perf & Start & Lic & Perf & Start & Lic & Perf & Start & Lic & Perf & DV \\
\hline 1010 & 2632 & 1078 & 157 & 656 & 813 & 1366 & 3489 & 4711 & 674 & 2153 & 2827 & N \\
\hline 12 & 26 & 38 & 2 & 6 & 8 & 15 & 40 & 53 & 10 & 26 & 36 & K \\
\hline 0.517 & 0.231 & 0.317 & 0.147 & 0.056 & 0.073 & 0.740 & 0.444 & 0.532 & 0.629 & 0.363 & 0.435 & Obs. r \\
\hline 0.572 & 0.236 & 0.328 & 0.148 & 0.056 & 0.074 & 0.950 & 0.478 & 0.593 & 0.740 & 0.381 & 0.466 & $\begin{array}{l}\text { Corrected } \\
\text { r }\end{array}$ \\
\hline 0.452 & 0.183 & 0.278 & -0.062 & -0.046 & -0.018 & 0.706 & 0.408 & 0.504 & 0.564 & 0.313 & 0.394 & $\begin{array}{l}\mathbf{9 9 \% ~ C I ~} \\
\text { Lower }\end{array}$ \\
\hline 0.561 & 0.268 & 0.347 & 0.298 & 0.133 & 0.142 & 0.763 & 0.471 & 0.552 & 0.674 & 0.400 & 0.465 & $\begin{array}{l}\mathbf{9 9 \%} \text { CI } \\
\text { Upper }\end{array}$ \\
\hline
\end{tabular}

Exhibit 4. University technology transfer meta-analysis results comparing fixed effects model and random effects model

\begin{tabular}{|c|c|c|c|c|c|c|c|c|c|c|c|c|}
\hline $\mathrm{E}$ & $\mathrm{E}$ & E & $\mathrm{P}$ & $\mathrm{P}$ & $\mathrm{P}$ & $\mathrm{O}$ & $\mathrm{O}$ & $\mathrm{O}$ & $\mathrm{H}$ & $\mathrm{H}$ & $\mathrm{H}$ & IV \\
\hline Start & Lic & Perf & Start & Lic & Perf & Start & Lic & Perf & Start & Lic & Perf & DV \\
\hline 0.517 & 0.231 & 0.317 & 0.147 & 0.056 & 0.073 & 0.740 & 0.444 & 0.532 & 0.696 & 0.363 & 0.435 & $\begin{array}{l}\text { Fixed } \\
\text { Pt Est }\end{array}$ \\
\hline 0.530 & 0.337 & 0.403 & 0.147 & 0.042 & 0.067 & 0.818 & 0.583 & 0.644 & 0.652 & 0.422 & 0.495 & $\begin{array}{l}\text { Random } \\
\text { Pt Est }\end{array}$ \\
\hline 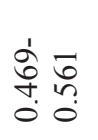 & 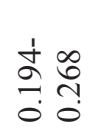 & 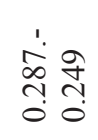 & 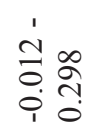 & 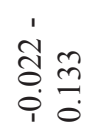 & $\frac{1}{8} \frac{1}{0}$ & 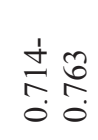 & $\begin{array}{l}\frac{1}{\sigma} \\
\stackrel{+}{f} \\
0\end{array}$ & $\begin{array}{l}\dot{1} \\
\vec{n} \tilde{n} \\
0\end{array}$ & $\begin{array}{ll}1 & + \\
0 & 0 \\
0 & 0 \\
0 & 0 \\
0 & 0\end{array}$ & 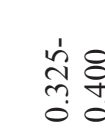 & 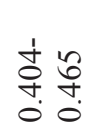 & $\begin{array}{l}\text { Fixed } \\
\text { LL-UL }\end{array}$ \\
\hline 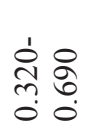 & $\begin{array}{l}\stackrel{1}{0} \\
\stackrel{n}{0} \stackrel{0}{n} \\
0\end{array}$ & 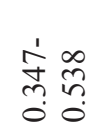 & 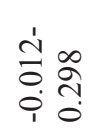 & $\begin{array}{l}\hat{0} \\
0 \\
i\end{array} \frac{\infty}{0}$ & $\begin{array}{ll}0 & 0 \\
8 & 0 \\
0 & 0 \\
0 & 1\end{array}$ & 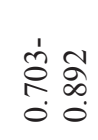 & ڤે̀े & 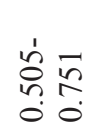 & 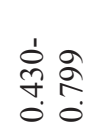 & 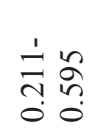 & तें & $\begin{array}{l}\text { Random } \\
\text { LL-UL }\end{array}$ \\
\hline 93.74 & 96.60 & 96.26 & 0.00 & 72.49 & 63.575 & 96.02 & 98.19 & 98.03 & 93.55 & 96.50 & 96.18 & $I^{\wedge} 2$ \\
\hline
\end{tabular}

It includes fixed effect point estimate sizes (Fixed Pt Est) for the effects and 95\% confidence intervals. Exhibit 4 also includes random effect point estimate sizes (Random Pt Est) for the effects and $95 \%$ confidence intervals. The confidence intervals for the fixed effect model results are narrower than the random effects model results. Also, the large studies have more impact under the fixed effect model than in the random effects model.

It is important to note that the effect sizes vary from study to study and these dispersions may be due to chance, sampling error or real differences in the effect sizes from one study to the next. Thus, the dispersion in 
effect sizes was analyzed for whether or not it is due to sampling error, chance or real differences in the correlations. The I-squared value is a measure of heterogeneity and it is listed in Exhibit 4. I^2 indicates the proportion of the observed variance that reflects the real difference in the studies.

The fixed effects model is based on the assumption that all of the studies are identical and have the same underlying true effect size; i.e. a single common effect. It assumes that any dispersion is due to sampling errors. In the first example of environmental factors correlated to start-up business formations, $\mathrm{I}^{\wedge} 2$ was 93.74 . This indicates that the variance of dispersion would be $94 \%$ as wide was depicted in the forest plots generated by the CMA software. So, the dispersion would be reduced but not by very much. Given that there are high $\mathrm{I}^{\wedge} 2$ values, there is likely dispersion which is due to more than just sampling error. Thus, the random effects model is the best model's results are the best results to use.

In addition, $\mathrm{Q}$, degrees of freedom (df) and $\mathrm{p}$ values to test the hypothesis of homogeneity were evaluated. The studies have heterogeneity and it is unlikely that dispersion is due to chance. When there is statistical heterogeneity, the random effects model may be useful to give a more conservative results due to the wider confidence intervals. However, this was not the basis for deciding whether to use the fixed effect model results rather than the random effects model results. That decision is based on the sampling method. Since this systematic review involved going to the literature, extracting studies, and culminated in the selection of 18 studies, these studies are obviously not identical and the effect size really does vary from one study to the next. Thus, the random effect model results are the more plausible. As shown in Exhibit 4, the only difference between the random model results and the fixed effect model results is that organizational inputs to licensing performance outputs have a large effect (unlike the results of the fixed effect model).

The existing literature is extended by testing four (4) hypotheses related to human, organizational, physical and external environmental resource inputs of TTO output performance. A discussion of the results related to each of the four (4) hypotheses follows:

- Hypothesis 1. Human resources are positively related to TTO performance in the areas of patent licensing and generating startups. Human resources are characterized by the TTO FTEs, TTO age and TTO legal expenditures for legal help.

As shown in Exhibit 4, the select human resources characterized by TTO age, TTO size and TTO expenditure on legal help measures had an observed and Fischer corrected correlation $r$ greater than 0.5 in relation to university start up business formation. However, the study results do not show a large effect size between TTO human resources and licensing performance. The overall effect of these human resources was near significant as evidenced by weighted average correlations just under the value of 0.5 . Thus, Hypothesis 1 is supported in part.

- Hypothesis 2. Organizational resources are positively related to TTO performance in the areas of patenting, licensing, and generating startups. These resources are faculty invention disclosures, university patent applications and university patents owned.

The university organizational resources researched in the selected studies for this systematic review included invention disclosures, patent applications and university patents owned. With respect to the evaluation of these organizational resources' relationship to overall technology transfer performance. Hypothesis 2 was not supported. These select organizational resources were positively related to overall performance and to university start up business formation. This was expected because without these resources, it is very difficult to execute intellectual property licenses and generate licensing revenue. It would also be difficult to increase start up business formations since a common university start-up business model is to license a university owned patent to the start up for cash or equity for the purpose of commercializing the patented invention. Thus, without the invention disclosures, patent applications and issued patents, this approach to technology transfer would not work.

- Hypothesis 3. Physical resources are positively related to TTO performance in the areas of patenting, licensing, and generating startups. These physical resources include incubators and medical schools.

The weighted average correlations for university physical resources including incubators and medical schools in relationship to overall technology commercialization performance in startup business formation and patent licensing were not large effects. Thus, Hypothesis 3 was not supported. 
- Hypothesis 4. External environmental munificence is positively related to TTO performance in the areas of patent licensing and generating startups.

The external environmental resources of research funding by industry and governmental agencies, GDP and regional R\&D intensity did not have a positive relation on the overall performance of technology transfer as defined by patent licenses executed, licensing revenues and startup business formations. However, when investigating the relationship of the environmental resources on licensing separate from start-up business formations, there was no positive relationship between environmental resources and licensing (i.e. executed patent licenses and licensing income). Yet, there was a positive relationship between the external environment and start up business formations. Thus, this systematic review provides confirmation that start-up business formations are positively correlated to the availability of external research and development sponsored funding, GDP and regional R\&D intensity.

\section{Conclusion}

Unfortunately, prior research contains conflicting evidence surrounding how key TTO resources attributes and characteristics of the environment relate to performance. Given the importance of TTOs, the lack of a comprehensive study, and that little theory has been leveraged to understand central TTO-performance relationships, insights from extant research was combined via this systematic review and meta-analysis to tell a more complete story.

Here, the Resource Based View and Theory of Environmental Munificence were applied and we find that the relationship between TTO human and organizational resources and start up business performance is where TTOs get the strongest returns. It was discovered that human and organizational resources are significant relative to startup business formations, patents, and licensing activities. The strongest effects were among the organizational and human inputs relative to licensing activities. The Resource Based View (RBV) teaches that when resources are hard to imitate, are valuable and rare, such as patented inventions, then they provide an organization with a competitive advantage. External environmental munificence also relates to TTO performance. The Theory on Environmental Munificence (TEM) (Castrogiovanni, 1991, 2002) teaches that environment external to the university is an important source of resources, and when environments are more munificent, it makes it easier for an organization to survive and prosper. Combined, the RBV and TEM explains the results of this meta-analysis research.

This analysis is useful because it can steer TTO managers and leaders into the direction of bolstering their human and organizational resources with their limited financial investments, rather than physical resources in order to improve performance success. Doing so will not only reconcile conflicting findings in extant research, but also will enable university leaders to optimize the use of their scarce resources.

\section{References}

Barney, Jay (1991). Firm resources and sustained competitive advantage. Journal of management 17(1), 99-120.

Barney, Jay B.; Arikan, A. M. . (2001). Resource-based view: origins and implications. In R. F. Hitt, Harrison, J. (Ed.), The Blackwell Handbook of Strategic Management (pp. 124-188). Malden, MA: Blackwell.

Bayh Dole Act, Pub. L. No. 96-517 (1980 December 12, 1980).

Borenstein, M.; Hedges, L.; Higgins, J.; Rothstein, H. (2005). Comprehensive Meta-Analysis. Englewood, NJ: Biostat.

Cardozo, Richard; Ardichvili, Alexandre; Strauss, Anthony (2011). Effectiveness of university technology transfer: an organizational population ecology view of a maturing supplier industry. The Journal of Technology Transfer 36(2), 173-202.

Carlsson, Bo; Fridh, Ann-Charlotte. (2002). Technology transfer in United States universities. Journal of Evolutionary Economics, 12(1), 199-232.

Castrogiovanni, Gary J. . (1991). Environmental Munihcence; A Theoretical Assessment. Academy of Management Review, 16(3), 542-565.

Castrogiovanni, Gary J. . (2002). Organization task environments: Have they changed fundamentally over time? Journal of Management, 28(2), 129-150.

Chapple, Wendy, Lockett, Andy, Siegel, Donald, Wright, Mike (2005). Assessing the relative performance of U.K. university technology transfer offices: parametric and non-parametric evidence. Research Policy, 34, 369384. 
Clarysse, Bart; Wright, Mike; Lockett, Andy; Mustar, Philippe; Knockaert, Mirjam. (2007). Academic spin-offs, formal technology transfer and capital raising. Industrial and Corporate Change, 16(4), 609-640.

Cochrane Handbook for Systematic Reviews of Interventions2011). J. P. G. Higgins, Sally (Ed.) Retrieved from www.handbook.cochrane.org

Cohen, Jacob. (1977). Statistical power analysis for the behavioral sciences. New York, NY: Academic Press.

Combs, James G.; Ketchen, David J.; Crook, T. Russell; Roth, Philip L. . (2011). Assessing cumulative evidence within 'macro'research: Why meta-analysis should be preferred over vote counting. Journal of Management Studies, 48(1), 178-197.

Crook, T. Russell; Ketchen, David J.; Combs, James G.; Todd, Samuel Y. . (2008). Strategic resources and performance: a meta-analysis. Strategic Management Journal 29(11), 1141-1154.

Curi, Claudia; Daraio, Cinzia; Llerena, Patrick. (2012). University technology transfer: how (in) efficient are French universities? Cambridge Journal of Economics 36(3), 629-654.

Friedman, Joseph, Silberman, Jonathan. (2003). University Technology Transfer: Do Incentives, Management, and Location Matter? Journal of Technology Transfer, 28, 17-30.

González-Pernía, José L., Kuechle, Graciela, Peña-Legazkue, Iñaki (2013). An Assessment of the Determinants of University Technology Transfer. Economic Development Quarterly.

Hamilton, Clovia. (2015). University Technology Transfer Information Processing from the Attention Based View. Paper presented at the Proceedings of the International Annual Conference of the American Society for Engineering Management International Annual Conference, Indianapolis, IN.

Hamilton, Clovia. (2017a). Emerging research institutions' technology transfer supply chain networks' sustainability: Budget resource planning tool development. IEEE Engineering Management Review, 45(4), 39-52.

Hamilton, Clovia. (2017b). HBCU Technology Transfer Supply Chain Networks Sustainability Budget Resource Planning Tool Development. Paper presented at the 38th International Annual Conference of the American Society for Engineering Management (ASEM 2017), Reimagining Systems Engineering and Management, Huntsville, AL.

Hamilton, Clovia; Schumann, David. (2016). Love and Hate in University Technology Transfer: Examining Faculty and Staff Conflicts and Ethical Issues The Contribution of Love, and Hate, to Organizational Ethics (pp. 95-122): Emerald Group Publishing Limited.

Ho, Mei Hsiu-Ching; Liu, John S.; Lu, Wen-Min; Huang, Chien-Cheng (2014). A new perspective to explore the technology transfer efficiencies in US universities. The Journal of Technology Transfer, 39(2), 247.

Hülsbeck, Marcel; Lehmann, Erik E.; Starnecker, Alexander (2013). Performance of technology transfer offices in Germany. The Journal of Technology Transfer, 1-17.

Lockett, Andy; Siegel, Donald; Wright, Mike; Ensley, Michael D. (2005). The creation of spin-off firms at public research institutions: Managerial and policy implications. Research Policy, 34(7), 981-993.

Lockett, Andy; Wright, Mike (2005). Resources, capabilities, risk capital and the creation of university spin-out companies. Research Policy 34, 1043-1057.

Markman, Gideon D., Phan, Phillip H., Balkin, David B., Gianiodis, Peter T. (2005). Entrepreneurship $\quad$ and university-based technology transfer. Journal of Business Venturing 20, 241-263.

Markman, Gideon D.; Gianiodisa, Peter T.; Phan, Phillip H.; Balkin, David B. . (2005). Innovation speed: Transferring university technology to market. Research Policy, 34, 1058-1075.

McGowan, Jessie; Sampson, Margaret Sampson; Salzwedel, Douglas M.; Cogo, Elise; Foerster, Vicki; Lefebvre, Carol (2016). PRESS peer review of electronic search strategies: 2015 guideline statement. Journal of clinical epidemiology, 75, 40-46.

Moher, David; Liberati, Alessandro; Tetzlaff, Jennifer; Altman, Douglas G.; Prisma Group. (2009). Preferred reporting items for systematic reviews and meta-analyses: the PRISMA statement. PLoS medicine 6(7).

Powers, Joshua B. . (2003). Commercializing academic research: Resource effects on performance of university technology transfer. The Journal of Higher Education, 74(1), 26-50.

Powers, Joshua B.; McDougall, Patricia (2005). Policy orientation effects on performance with licensing to start-ups and small companies. Research Policy, 34(7), 1028-1042.

Rogers, Everett M.; . (2000). Assessing the Effectiveness of Technology Transfer Offices at U.S. Research Universities. Journal of the Association of University Technology Managers, 12(1), 47-80.

Sampson, Margaret; McGowan, Jessie;; Lefebvre, Carol.; Moher, David; Grimshaw, Jeremy. (2008). PRESS: Peer Review of Electronic Search Strategies. Ottawa, ON, Canada. 2014

Schmidt, Frank L.; Hunter, John E. . (2015). Methods of meta-analysis: Correcting error and bias in research findings (3rd ed.). Thousand Oaks, CA: Sage Publications. 
Seashore Louis, Karen; Blumenthal, David; Giuck, Michael E.; Stoto, Michael A. (1989). Entrepreneurs in Academe: An Exploration of Behaviors among Life Scientists. Administrative Science Quarterly, 34, 110131.

Siegel, Donald S., Waldman, David, Link, Albert (2003). Assessing the impact of organizational practices on the relative productivity of university technology transfer offices: an exploratory study. Research Policy, 32, 27-48.

Sine, Wesley David; Shane, Scott; Di Gregorio, Dante (2003). The halo effect and technology licensing: The influence of institutional prestige on the licensing of university inventions. Management Science, 49(4), 478-496.

Swamidass, Paul M., Valusa, Venubabu (2009). Why university inventions rarely produce income? Bottlenecks in university technology transfer. Journal of Technology Transfer, 34, 343-363.

Van Looy, Bart; Landoni, Paolo; Callaert, Julie; Van Pottelsberghe, Bruno; Sapsalis, Eleftherios; Debackere, Koenraad. (2011). Entrepreneurial effectiveness of European universities: An empirical assessment of antecedents and trade-offs. Research Policy, 40(4), 553-564.

Wiesendanger, Hans. (2000). A History of OTL. 2014

\section{About the Author}

Clovia Hamilton earned a $\mathrm{PhD}$ in Industrial \& Systems Engineering with a concentration in Engineering Management from the University of Tennessee Knoxville. Dr. Hamilton has also earned a JD from Atlanta's John Marshall Law School, a Master of Laws (LLM) in Intellectual Property Law from the University of Illinois at Urbana-Champaign and a MBA from Wesleyan College. Clovia currently serves as an Assistant Professor of Management in the Winthrop University College of Business Administration. She teaches operations management and business law and ethics. Her research interests are focused on university and federal lab technology commercialization and entrepreneurship. Dr. Hamilton is a former USPTO patent examiner, a registered patent attorney and a member of the State Bar of Georgia. She is also a member of AUTM, AOM, PhD Project, INFORMS, IEEE, IAAM, Southern Management Association, Society of Business Ethics, Association of Business Communications and several other management focused trade organizations. 